\title{
Hubungan Usia Kronologis Awal Masuk Sekolah dengan Prestasi Belajar Siswa Sekolah Dasar
}

\author{
Assyifa Fauzia ${ }^{1}$, Deswalantri ${ }^{2}$ \\ ${ }^{1}$ Program Studi Pendidikan Bimbingan dan Konseling Fakultas Tarbiyah dan Ilmu Keguruan IAIN Bukittinggi, \\ Indonesia \\ e-mail: assyifafauzia10@gmail.com
}

\begin{abstract}
ABSTRAK. This research was conducted based on the problem that it was found that there were still students who were enrolled in school at the age that had been determined by the government (seven years). The result of an interviwe with the parik putuih integrated Islamic Elemtery School teacher stated that there were students who entered school in 2016 who were under the age of seven. This study aims to see whether on variable has a relationship with other variables. Data collection wascarried out using the documentation method to see the chronological age at the beginning of school entry and semester I and II grades from grade 1 to grade 3 elementary shool. This study uses data analysis spearman Rank Correlation (Grade Correlation). The results obtained using the Spearman Rank Correlation technique otained hit 0,352 and tab at a significant level of $5 \%$ is 0.364 . It is proven that there is no relationship between crhonological age at the beginning of school and student achievement. The result show that H_0 is accept and H_a is rejected. So it can be concluded that the level of relationship between crhonological age at the beginning of school entry and student achievement at SDIT Baiturrahim Parik Putuih Kabupaten Agam is at a low level or there is not relationship.
\end{abstract}

Kata kunci: Realtionship; Early Chronological Age of School Entry; Learning Achievement

\section{PENDAHULUAN}

Pendidikan adalah sektor yang paling penting dalam upaya pembangunan nasional, menjadi andalan utama yang berfungsi dalam upaya meningkatkan kualitas hidup manusia, dimana iman dan takwa kepada Tuhan Yang Maha Esa menjadi sumber motivasi dalam segala bidang kehidupan. Pendidikan dapat membantu para siswa untuk mengembangkan potensi dirinya kearah yang positif. Untuk mewujudkan pembangunan nasional bidang pendidikan diperlukan peningkatan dan penyempurnaan penyelenggaraan pendidikan yang disesuaikan dengan ilmu pengetahuan dan teknologi.

Berkaitan dengan usia dan prestasi belajar siswa maka pendidikan merupakan hal wajib bagi kehidupan manusia, bahkan islam adalah ilmu pengetahuan dan tiada sempurna agama seseorang yang hidup dalam kebodohan dan kegelapan. Hal ini diterangkan Allah SWT dalam AlQur'an Surat Al-Mujadalah Ayat 11 yang berbunyi:

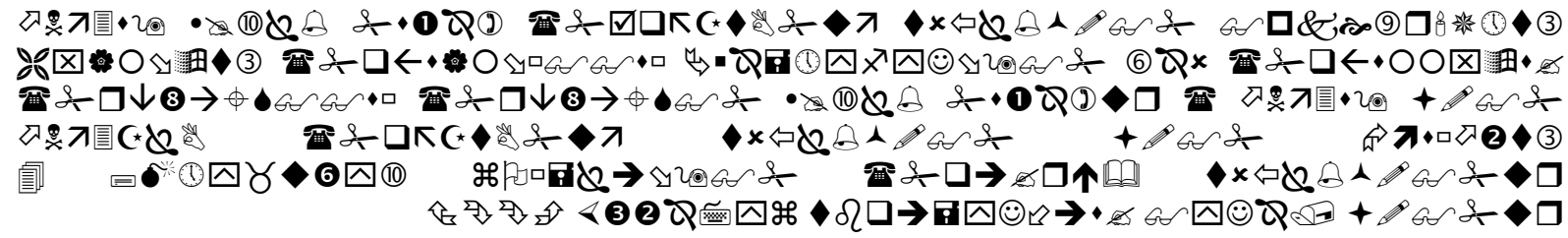

11. Hai orang-orang beriman apabila kamu dikatakan kepadamu: "Berlapang-lapanglah dalam majlis", Maka lapangkanlah niscaya Allah akan memberi kelapangan untukmu. dan apabila dikatakan: "Berdirilah kamu", Maka 
berdirilah, niscaya Allah akan meninggikan orang-orang yang beriman di antaramu dan orang-orang yang diberi ilmu pengetahuan beberapa derajat. dan Allah Maha mengetahui apa yang kamu kerjakan.

Ilmu dalam hal ini tentu saja tidak hanya berupa pengetahuan agama tetapi juga berupa pengetahuan yang relevan dengan tuntutan kemajuan zaman. Muhibbin Syah menyebutkan; "ilmu tersebut juga harus bermanfaat bagi kehidupan orang banyak di samping begi kehidupan diri pemilik ilmu itu sendiri". (Muhibbinn Syah, 2010). Pendidikan sendiri ditujukan untuk mengembangkan diri, segala potensi yang ada baik secara rohani maupun jasmani. Sebagaimana tujuan pendidikan yang tertuang dalam Undang-Undang Republik Indonesia No. 20 tahun 2003 pasal 3 tentang Sistem Pendidikan Nasional, yaitu: Tujuan Pendidikan Nasional, mengembangkan kemampuan dan membentuk watak serta peradaban bangsa yang bermartabat dalam rangka mencerdaskan kehidupan bangsa. Betujuan untuk mengembangkan potensi peserta didik agar menjadi manusia yang beriman dan bertaqwa kepada Tuhan Yang Maha Esa, berakhlak mulia, sehat, berilmu, cakap, kreatif, mandiri dan menjadi warga negara yang demokratis serta bertanggung jawab.

Prestasi belajar merupakan hasil dari pengukuran terhadap peserta didik yang meliputi beberapa faktor yaitu: foktor kognitif, afektif dan psikomotor setelah mengikuti proses pembelajaran yang diukur dengan menggunakan instrumen tes atau instrumen yang relevan. Selanjutnya Mar'atun Aslamiyah Rizally mengatakan bahwa; "Aktivitas belajar bagi setiap individu tidak selamanya lancar, ada yang cepat menangkap apa yang dipelajari dan ada yang malah sebaliknya. Setiap individu memang tidak sama, perbedaan inilah yang membuat individu memiliki perbedaan tingkah laku belajar di kalangan anak didik". (Mar'atun Aslamiyah Rizally, 2011).

Mengenai usia awal masuk sekolah di Indonesia telah diatur, melalui peraturan Menteri Pendidikan dan Kebudayaan Republik Indonesia Nomor 44 Tahun 2019 pasal 5 mengatur tentang persyaratan usia masuk siswa baru. Persyaratan calon peserta didik baru kelas 1 (satu) Sekolah Dasar (SD) berusia tujuh tahun sampai dengan dua belas tahun atau paling rendah enam tahun pada tanggal 1 Juli tahun berjalan. Sekolah wajib menerima peserta didik yang berusia tujuh sampai dengan dua belas tahun. Pengecualian syarat usia paling rendah enam tahun sebagaiman dimaksud pada ayat (1) huruf b yaitu paling rendah lima tahun enam bulan pada tanggal satu Juli tahun berjalan yang diperuntukkan bagi calon peserta didik yang memiliki potensi kecerdasan dan/ ataubakat istimewa dan kesiapan psikis yang dibuktikan dengan rekomendasi tertulis dari psikologis profesional. Dalam hal psikologis profesional sebagaimana dimaksud pada ayat (3) tidak tersedia, rekomendasi dapat dilakukan oleh dewan guru Sekolah.

Menurut peraturan yang telah ditetapkan bahwa syarat usia masuk Sekolah Dasar/Madrasah Ibtidaiyah (SD/MI) minimal telah berusia tujuh tahun, namun banyak terjadi dilapangan ada orang tua mendaftarkan anaknya pada usia dibawah tujuh tahun. Pada dasarnya banyak ilmuan yang mengatakan bahwa pada saat anak berumur tujuh tahun anak memiliki kesiapan mental dan fisik untuk dapat menjalankan segala aktivitas disekolah. Apabila anak dipaksakan untuk masuk sekolah sebelum cukup usia sekolah, anak akan merasa terbebani dengan kewajiban-kewajiban dalam bersekolah yang pada akhirnya bukan meningkatkan prestasi malahan menjadikan anak ketinggalan. Mengenai hal ini perilaku orang tua yang merasa terlalu percaya diri akan keistimewaan anaknya dapat membuat anak-anak merasa lelah yang kehilangan kegembiraan sebagai anak-anak.

Mar'atun Aslamiyah Rizally juga mengatakan; “terkait dengan hal tersebut juga dikuatkn oleh para ahli psikologi yang menyatakan bahwa perbedaan umur beberapa bulan saja pada anakanak akan terlihat perbedaan tugas perkembangannya". (Mar'atun Aslamiyah Rizally, 2011). Terkait hal tersebut peneliti mengidentifikasi penelitian dari segi usia awal masuk sekolah dasar dengan prestasi belajar siswa. Tujuan penelitian ini untuk membuktikan adakah hubungan usia 
kronologis awal masuk sekolah dengan prestasi belajar siswa SDIT Baiturrahim Parik Putuih Kabupaten Agam.

\section{METODOLOGI}

Berdasarkan masalah yang akan diteliti yaitu "Hubungan Usia Kronologis Awal Masuk Sekolah Dengan Prestasi Belajar Siswa SDIT Baiturrahim Parik Putuih”, maka jenis penelitian yang digunakan penulis adalah penelitian korelasi. Penelitian korelasional adalah untuk mencari bukti (berlandaskan data yang ada), apakah memang benar antara variabel yang satu dan variabel yang lain terdapat hubungan atau korelasi. Penelitian ini membahas tentang korelasi antara hubungan usia kronologis awal masuk sekolah dengan prestasi belajar siswa, dengan asumsi bahwa usia kronologis awal masuk sekolah dasar (usia lima dan enam tahun) sebagai variabel X dan prestasi belajar siswa (nilai rapor siswa kelas 5 dari kelas 1-3, semsester I dan II) sebagai variabel Y. Penelitian ini berusaha untuk mengungkapkan kenyataan dilapangan yang berhubngan dengan hubungan usia kronologis awal masuk sekolah dengan prestasi belajar siswa SDIT Baiturrahim Parik Putuih Kabupaten Agam.

Populasi dalam penelitian ini adalah siswa SDIT Baiturrahim Parik Putuih Kabupaten Agam kelas 4 dan 5 yang berjumlah 81 siswa, untuk sampelnya berjumlah 30 siswa yang menjadi sampel adalah siswa kelas 5 yang berumur 5 dan 6 tahun saat masuk sekolah dasar. Teknik yang digunakan adalah teknik spearman rank correlation (korelasi tata jenjang).

Selanjutnya membandingkan nilai hasil perhitungan $\varrho$ hit dengan $\varrho$ tab pada tabel signifikan 5\% atau 1\% dengan kemungkinan: (1) Jika $\varrho$ hit $\geq \varrho$ tab berarti ada hubungan atau korelasi usia kronologis awal masuk sekolah dengan prestasi belajar siswa SDIT Baiturrahim Parik Putuih Kabupaten Agam. (2) Jika $\varrho$ hit $<\varrho$ tab berarti tidak ada hubungan atau korelasi usia kronologis awal masuk sekolah dengan prestasi belajar siswa SDIT Baiturrahim Parik Putuih Kabupaten Agam. (3) Menginterpretasikan dengan tabel nilai-nilai rho pada tabel tentang pedoman memberikan interpretasi koefesien korelasi. (4) Kemudian melakukan uji signifikan spearman rank correlation (korelasi tata jenjang), langsung dikonsultasikan pada tabel rho.

Data penelitian ini dikumpulkan menggunakan metode dokumentasi dimana untuk usia anak pada awal masuk sekolah menggunakan data dokumentasi daftar nama siswa kelas $\mathrm{V}$ dan untuk prestasi belajar diperoleh dari nilai rapor yang telah dirata-rata keseluruhan nilai rapor angka siswa kelas V dari rapor kelas I sampai dengan kelas III.

\section{TEMUAN DAN DISKUSI}

Temuan penelitian menunjukan bahwa tidak adanya atau tidak terdapat hubungan usia kronologis awal masuk sekolah dengan prestasi belajar siswa SDIT Baiturrahim Parik Putuih Kabupaten Agam mulanya dimulai dengan tahap perencanaan yang meliputi: pertemuan dengan Kepala Sekolah, guru walikelas dan guru Tata Usaha untuk melakukan wawancara, teknik ini dilakukan dengan cara waancara tidak terstuktur maksudnya wawancara bebas dimana peneliti tidak menggunakan pedoman wawancara yang telah tersusun secara sistematis dan lengkap untuk pengumpulan data. Fokus penelitian yaitu siswa kelas $\mathrm{V}$ yang usia awal masuk sekolah berusia lima dan enam tahun. Penelitian ini dilatarbelakangi adanya persoalan yang ditemukan di lapangan yang menunjukkan bahwa masih ada anak yang bersekolah di bawah usia yang telah di tentukan oleh pemerintah untuk tingkat Sekolah Dasar (SD) yaitu usia tujuh tahun. Sebagaimana mengenai usia awal masuk sekolah ini di Indonesia telah diatur melalui Peraturan Menteri Pendidikan dan Kebudayaan Republik Indonesi Nomor 44 Tahun 2019 pasal 5 mengatur tentang persyaratan usia masuk siswa baru. Persyaratan calon peserta didik baru kelas 1 (satu) Sekolah Dasar (SD) berusia tujuh tahun sampai dengan dua bels tahun atau paling rendah enam tahun pada tanggal 1 Juli tahun berjalan. Sekolah wajib menerima peserta didik yang berusia tujuh tahun sampai dengan 
dua belas tahun. Pengecualian syarat usia paling rendah lima tahun enam bulan pada tanggal satu Juli tahun berjalan yang diperuntukkan bagi calon peserta didik yang memiliki potensi kecerdasan dan/ atau bakat istimewa dan kesiapan psikis yang dibuktikan dengan rekomendasi tertulis dari psikologis profesional.

Penelitian ini merupakan penelitian korelasional dengan menggunakan pendekatan kuantitatif. Penelitian juga membahas tentang korelasi anatara hubungan usia kronologis awal masuk sekolah terhadap prestasi belajar siswa dengan asumsi bahwa usia kronologis awal sebagai variabel $\mathrm{X}$ dan prestasi belajar siswa sebagai variabel Y. Maksud dari variabel tersebut adalah variabel bebas yang sering disebut sebagai variabel $\mathrm{X}$ merupakan variabel yang mempengaruhi atau yang menjadi sebab perubahan, sedangkan variabel $\mathrm{Y}$ atau di sebut dengan variabel terikat merupakan variabel yang dipengaruhi atau yang menjadi akibat, karena adanya variabel bebas. Tujuan penelitian ini untuk membuktikan adakah hubungan usia kronologis awal masuk sekolah dengan prestasi belajar siswa SDIT Baiturrahim Parik Putuih Kabupaten Agam. Hasil penelitian yang penulis dapatkan merupakan hasil dari tujuan penelitian yang penulis lakukan. Mengenai penelitian yang dilakukan, peneliti berusaha untuk mengungkapkan kenyataan dilapangan yang berhubungan dengan hubungan usia kronologis awal masuk sekolah dengan prestasi belajar siswa SDIT Baiturrahim Parik Putuih Kabupaten Agam.

Untuk memperoleh hasil penelitian, penulis menggunakan teknik pengumpulan data, adapun yang dimaksud dengan teknik pengumpulan data adalah cara yang dipakai untuk mengumpulkan data dengan menggunakan metode-metode tertentu. Salah satu metode yang digunakan yaitu metode dokumentasi yang mana data dari penelitian ini di ambil dari daftar nama siswa dan untuk prestasi belajar diperoleh dari nilai rata-rata rapor semester I dan II dari kelas 1 3 siswa SDIT Baiturrahim Parik Putuih Kabupaten Agam yang fokus penelitian pada anak kelas $\mathrm{V}$ yang usia awal masuk sekolah berusia lima dan enam tahun.

Penelitian ini merupakan penelitian kuantitatif, teknik analisis data yang digunakan yaitu Spearman Rank Correlation (teknik korelasi tata jenjang) yang mana teknik ini merupakan salah satu teknik untuk mencari korelasi antar dua variabel, korelasi ini tidak menggunakan data interval tapi dalam skala ordinal, data mungkin dalam bentuk ordinal/pangkat atau mungkin baru ditentukan pangkatnya kemudian, misalkan jika data berbentuk ratio maka perlu diubah menjadi data ordinal sebelum dianalisis. Sebelum data diolah menggunakan rumus Spearman Rank Correlation, data dokumentasi berupa daftar nama siswa (populasi penelitian) yang dicantumkan pada tabel 1 sedangkan hasil rata-rata rapor semester ke dalam tabel 2, nilai yang diperoleh masing-masing siswa setelah itu dicari rata-rata nilai yang diperoleh masing-masing siswa, penelitian ini difokuskan pada siswa yang masuk sekolah dasar pada usia lima dan enam tahun di SDIT Baiturrahim Parik Putuih Kabupaten Agam.

\section{Tabel 1. Populasi Penelitian}

\begin{tabular}{cccccc}
\hline \multicolumn{6}{c}{ Usia Siswa } \\
No & Kelas & $\mathbf{5}$ tahun & 6 Tahun & 7 Tahun & 8 Tahun \\
\hline 1 & IV & 1 & 24 & 10 & 1 \\
2 & V & 6 & 24 & 8 & 2 \\
Total & & 7 & 48 & 18 & 3 \\
\hline
\end{tabular}

Hasil rata-rata yang telah penulis olah maka tahap selanjutnya penulis mendistribusikan nilai tersebut kedalam tabel 2 . 
Tabel 2. Hasil Usia (X) dan Prestasi Belajar siswa (Y)

\begin{tabular}{|c|c|c|c|c|c|c|}
\hline $\begin{array}{c}\text { Non } \\
\text { Subjek }\end{array}$ & $\mathbf{X}$ & $\mathbf{Y}$ & Rank X & Rank Y & $\mathbf{D}$ & $d^{2}$ \\
\hline 1 & 5 & 90 & 27,5 & 4 & 23,5 & 552,25 \\
\hline 2 & 5 & 77 & 27,5 & 30 & -25 & 6,25 \\
\hline 3 & 6 & 88 & 12,5 & 13,5 & -1 & 1 \\
\hline 4 & 6 & 90 & 27,5 & 4 & 8,5 & 72,25 \\
\hline 5 & 6 & 85 & 12,5 & 19 & $-6,5$ & 42,25 \\
\hline 6 & 6 & 85 & 12,5 & 19 & $-6,5$ & 42,25 \\
\hline 7 & 6 & 80 & 12,5 & 24,5 & -12 & 144 \\
\hline 8 & 6 & 89 & 12,5 & 8 & 4,5 & 20,25 \\
\hline 9 & 6 & 83 & 12,5 & 22 & $-9,5$ & 90,25 \\
\hline 10 & 6 & 79 & 12,5 & 27 & $-14,5$ & 210,25 \\
\hline 11 & 6 & 84 & 12,5 & 21 & $-8,5$ & 72,25 \\
\hline 12 & 5 & 78 & 27,5 & 28,5 & -1 & 1 \\
\hline 13 & 6 & 85 & 12,5 & 19 & $-6,5$ & 42,25 \\
\hline 14 & 6 & 89 & 27,5 & 8 & 4,5 & 20,25 \\
\hline 15 & 5 & 79,3 & 12,5 & 26 & 1,5 & 2,25 \\
\hline 16 & 6 & 88 & 27,5 & 13,5 & -1 & 1 \\
\hline 17 & 6 & 80 & 27,5 & 24,5 & -12 & 144 \\
\hline 18 & 6 & 89,2 & 27,5 & 6 & 6,5 & 42,25 \\
\hline 19 & 6 & 90 & 27,5 & 4 & 8,5 & 72,25 \\
\hline 20 & 6 & 78 & 27,5 & 28,5 & -16 & 256 \\
\hline 21 & 6 & 87,2 & 27,5 & 16 & $-3,5$ & 12,25 \\
\hline 22 & 6 & 82 & 27,5 & 23 & $-10,5$ & 110,25 \\
\hline 23 & 5 & 93 & 12,5 & 1 & 26,5 & 702,25 \\
\hline 24 & 6 & 91,2 & 27,5 & 2 & 10,5 & 110,25 \\
\hline 25 & 6 & 88 & 27,5 & 13,5 & -1 & 1 \\
\hline 26 & 6 & 88,4 & 27,5 & 10 & 2,5 & 6,25 \\
\hline 27 & 5 & 85,4 & 12,5 & 17 & 10,5 & 110,25 \\
\hline 28 & 6 & 88,3 & 27,5 & 11 & 1,5 & 2,25 \\
\hline 29 & 6 & 89 & 27,5 & 8 & 4,5 & 20,25 \\
\hline
\end{tabular}

Selanjutnya untuk mengetahui hubungan usia kronologis awal masuk sekolah (variabel X) dengan prestasi belajar siswa SDIT Baiturrahim Parik Putuih Kabupaten Agam (variabel Y) maka penulis menggunakan teknik korelasi Spearman Rank Correlation (korelasi tata jenjang), 
teknik ini bertujuan untuk mengetahui ada tidaknya korelasi (hubungan) yang signifikan pada dua variabel. Ada beberapa langkah yang penulis lakukan untuk memperoleh data yaitu : (a). Mengumpuklan data sampel (b). Setelah data sampel terkumpul, selanjutnya peneliti mendistribusikan skor X dan Y ke dalam tabel 2. (c). Kemudian data didistribusikan kedalam tabel, langkah berikutnya peneliti mengolah data kedalam rumus spearman rank correlation (korelasi tata jenjang).

Hasil yang diperoleh yaitu:

$$
\begin{aligned}
\text { rho } & =1-\left(6 \sum \sum_{i} \mathrm{~d}^{\wedge} 2\right) /\left(\mathrm{n}\left(\mathrm{n}^{\wedge} 2-1\right)\right) \\
& =1-(6 \times 2910,5) /\left(30\left(\left[30 \rrbracket^{\wedge} 2-1\right)\right)\right. \\
& =1-17463 / 26970 \\
& =1-0,648 \\
& =0,352
\end{aligned}
$$

Hasil perhitungan didapat rho $=0,352$. Selanjutnya apabila kita lihat besaran rho yang diperoleh (yaitu $=0,352)$ ternyata terletak antara $(0,20-0,399)$. Berdasarkan pedoman memberikan interpretasi pada tabel 3 terhadap angka Indeks Korelasi spearman rank correlation secara kasar dapat dinyatakan bahwa korelasi antara Variabel X dan Variabel Y tidak terdapat korelasi atau dapat dinyatakan korelasi (hubungan) rendah sehingga tidak ada korelasi (hubungan) antara Variabel X (usia kronologis awal masuk sekolah dasar dan Variabel Y (prestasi belajar siswa).

Tabel 3. Pedoman Untuk Memberikan Interpretasi Koefesien Korelasi

\begin{tabular}{cl}
\hline Interval Koefisien & Tingkat Hubungan \\
\hline $0,00-0,199$ & Sangat Rendah \\
$0,20-0,399$ & Rendah \\
$0,40-0,599$ & Sedang \\
$0,60-0,799$ & Kuat \\
$0,80-1,000$ & Sangat Kuat \\
\hline
\end{tabular}

Selanjutnya Uji korelasi spearman rank correlation dapat dilakukan secara praktis, tetapi dapat dikonsultasikan pada tabel spearman rank correlation tabel 4, dari tabel 4 dapat dilihat bahwa, $\mathrm{n}=$ 30, taraf kesalahan 5\%

Tabel 4. Nilai-Nilai rho

\begin{tabular}{ccc}
\hline $\mathbf{N}$ & \multicolumn{2}{c}{ Taraf Signif } \\
& $\mathbf{5 \%}$ & $\mathbf{1 \%}$ \\
\hline 5 & 1,000 & \\
6 & 0,886 & 1,000 \\
7 & 0,786 & 0,929 \\
8 & 0,738 & 0,881 \\
9 & 0,683 & 0,833 \\
10 & 0,648 & 0,794 \\
12 & 0,591 & 0,777 \\
14 & 0,544 & 0,715 \\
16 & 0,506 & 0,665 \\
18 & 0,475 & 0,591 \\
20 & 0,450 & 0,562 \\
22 & 0,428 & 0,537 \\
24 & 0,409 & 0,537 \\
26 & 0,392 & 0,515 \\
28 & 0,377 & 0,496 \\
30 & 0,364 & 0,478 \\
\hline
\end{tabular}


Harga $\varrho$ tabel $=0,364$. Sesuai ketentuannya bila $\varrho$ hitung lebih kecil dari $\varrho$ tabel, maka H_0 diterima dan H_a ditolak. Tetapi sebaliknya bila $\varrho$ hitung lebih besar dari $\varrho$ tabel maka H_a diterima. Hal ini berarti $\varrho$ hitung $0,352<\varrho$ tabel 0,364 sehingga $\mathrm{H} \_0$ diterima sedangkan $\mathrm{H} \_a$ ditolak. Dapat disimpulkan bahwa hubungan usia kronologi awal masuk sekolah dengan prestasi belajar siswa SDIT Baiturrahim Parik Putuih Kabupaten Agam dapat dinyatakan tidak ada hubungan.

Setelah dilakukan analisis data penelitian dapat dilihat secara statistik bahwa tidak terdapat hubungan atau korelasi usia kronologis awal masuk sekolah terhadap prestasi belajar siswa. Hal ini mengisyaratkan tidak terdapat persoalan pada anak yang masuk Sekolah Dasar pada usia kurang dari tujuh tahun. Sebagaimana pada fase anak usia sekolah dasar, siswa mampu membedakan mana yang baik dan mana yang buru, mereka juga mengetahui mana yang harus diprioritaskan dan mana yang tidak.

Berdasarkan hasil penelitian dan perhitungan yang telah peneliti lakukan dengan menggunakan rumus spearman rank correlation menunjukan bahwa $\varrho$ hitung 0,352 lebih kecil dari $\varrho$ tabel 0,364 , maka dapat diketahui bahwa tidak terdapat hubungan (korelasi) yang signifikan antara usia kronologis awal masuk sekolah dengan prestasi belajar siswa di SDIT Baiturrahim Parik Putuih Kabupaten Agam. Berdasarkan perhitungan kriteria diatas dapat disimpulkan bahwa H_0 diterima dan H_a ditolak, sehingga diperoleh suatu interpretasi bahwa tidak adanya hubungan usia koronolgis awal masuk sekolah dengan prestasi belajar siswa di SDIT Baiturrahim Parik Putuih Kabupaten Agam. Hal ini berarti tidak masalah jikalau anak-anak yang berusia kurang dari usia ideal masuk sekolah (usia kurang dari tujuh tahun) untuk masuk Sekolah Dasar (SD). Hal tersebut sesuai dengan penelitian sebelumnya yang dilakukan oleh Mar'atun Aslamiya Rizally bahwa tidak terdapat pengaruh usia awal masuk sekolah terhadap prestasi belajar siswa, hasil ini didapat setelah dilakukan analisis data terhadap nilai prestasi belajar siswa, dan diperoleh hasil bahwa tidak terdapat hubungan anatara usia awal masuk sekolah dengan prestasi belajar, yang mana perbedaan penelitian ini dengan peneliti sebelumnya yaitu, dalam penelitian ini prestasi belajar diambil berdasarkan hasil belajar (nilai rapor) kelas I sampai dengan kelas III semester I dan II, sedangkan dalam penelitian sebelumnya yang dilakukan prestasi belajar diambil berdasarkan nilai hasil belajar kelas I sampai dengan VI semester I.

Faktor-faktor lain yang dapat mempengaruhi prestasi belajar yang tidak dikontrol, anatara lain: (a). Faktor yang bersumber dari diri sendiri, maksudnya timbul dalam diri siswa, seperti kurang minat pada mata pelajaran tertentu, kesehatan yang sering terganggu dan sebagainya. (b) Faktor yang bersumber dari lingkungan keluarga, seperti broken home, kurangnya pengawasan keluarga dan lainnya. (c) Faktor yang yang bersumber dari lingkungan masyarakat, yang berhubungan dengan pergaulan sasama teman sebaya sehingga dapat mengganggu belajar siswa.

Setelah dilakukan analisis data penelitian dapat dilihat secara statistik bahwa tidak terdapat hubungan atau korelasi usia kronologis awal masuk sekolah terhadap prestasi belajar siswa. Hal ini mengisyaratkan tidak terdapat persoalan pada anak yang masuk Sekolah Dasar pada usia kurang dari tujuh tahun. Sebagaimana pada fase anak usia sekolah dasar, siswa mampu membedakan mana yang baik dan mana yang buru, mereka juga mengetahui mana yang harus diprioritaskan dan mana yang tidak.

Sebagaimana pada fase anak usia sekolah dasar, siswa mampu membedakan mana yang baik dan mana yang buru, mereka juga mengetahui mana yang harus diprioritaskan dan mana yang tidak. Berdasarkan hasil data analisis maka dapat disimpulkan bahwa usia tidak berpengaruh besar terhadap prestasi belajar siswa, akan tetapi proses penerimaan siswa masuk sekolah dasar tetap pada peraturan pemerintah yang telah ditetapkan, sebagaimana syarat masuk usia sekolah dasar ialah usia tujuh tahun, untuk usia enam tahun diperbolehkan sedangkan usia kurang dari enam tahun harus ada rekomendasi tertulis dari psikolog profesional. 
Adapun keterbatasan dalam penelitian ini, peneliti menyadari dalam penelitian banyak kendala dan hambatan. Hal tersebut bukan karena faktor kesengajaan, akan tetapi akan adanya keterbatasan dalam penelitian. Keterbatasan dalam penelitian diantaranya:

\section{Faktor Waktu}

Waktu merupakan bagian terpenting dalam penelitian ini menjadi fakta kendala yang berpengaruh terhadap hasil penelitian. Karena hal ini terbatas pada waktu dimana peneliti melakukan penelitian, tidak selalu sama dengan waktu yang berbeda,

\section{Faktor Kemampuan}

Dalam hal kemampuan peneliti tidak lepas dari pengetahuan, dengan hal demikian peneliti menyadari keterbatassan kemampuan khususnya dalam pengetahuan untuk membuat karya ilmiah. Tetapi peneliti sudah berusaha dengan semapu peneliti agar penelitian ini dapat terlaksana dengan baik dan semaksimal mungkin untuk melakukan penelitian ini sesuai dengan kemampuan keimuan serta bimbingan dari dosen pembimbing.

\section{Data penelitian}

Penelitian ini hanya mengambil sampel 30 responden (siswa) dari kelas IV dan kelas V yang berjumlah 81, dengan menggunakan sampel dengan teknik Purposive Sampling. Oleh karena itu kemungkinan ada perbedaan hasil apabila dilakukan pada obyek penelitian yang lain.

Meskipun banyak hambatan dalam penelitian ini, peneliti bersyukur karena penelitian ini dapat terselesaikan dengan baik dan lancar atas izin Allah serta izin dari kepala sekolah dan pihak yang berpartisipasi dalam penelitian ini.

\section{KESIMPULAN}

Berdasarkan hasil penelitian, yang dilaksanakna di SDIT Baiturrahim Parik Putuih Kabupaten Agam yang bertujuan untuk mengetahui apakah terdapat hubungan usia kronologis awal masuk sekolah dengan prestasi belajar siswa maka dapat disimpulkan bahwa hasil penelitian yang telah dilaksanakan menggunakan teknik korelasi spearman rank yang menghasilkan $\varrho$ hit $<\varrho$ tab maka H_0 diterima dan $\mathrm{H} \_$a ditolak, dengan demikian perhitungan $\varrho$ hit $=0,352$ dan $\varrho$ tab pada taraf signifikan 5\% adalah 0,364 terbukti bahwa tidak ada hubungan usia kronologis awal masuk sekolah dengan prestasi belajar siswa SDIT Baiturrahim Parik Putuih Kabupaten Agam.

\section{SARAN}

Berdasarkan hasil penelitian tentang hubungan usia kronologis awal masuk sekolah dengan prestasi belajar siswa SDIT Baiturrahim Parik Putuih Kabupaten Agam, maka untuk mengoptimalisasikan pemanfaatan hasil penelitian ini, maka penulis memberikan saran sebagai berikut: (1) Kepada Kepala Sekolah, disarankan agar tidak apa-apa menerima siswa yang berusia kurang dari tujuh tahun tetapi tetap berpatokan pada peraturan pemerintah yang telah ditetapkan karena pada penelitian ini terbukti tidak adanya hubungan antara usia kronologis awal masuk sekolah terhadap prestasi belajar siswa terutama pada siswa yang berusia lima tahun. (2) Kepada guru, disarankan dalam memberikan pemahaman atau mengajar siswa untuk dapat melihat kemampuan yang dimiliki masing-masing siswa, karena setiap siswa memiliki kemampuan yang berbeda-beda. (3) Kepada peneliti selanjunya, disarankan agar memperluas penelitian ini dengan mengambil indikator-indikator seperti faktor yang dapat mempengaruhi prestasi belajar. 


\section{REFERENSI}

Kementerian Pendidikan Nasional dan Kebudayaan Republik Indonesia. 2019. Peraturan Menteri Pendidikan Dan Kebudayaan Republik Indonesia Nomor 44 Tahun 2019 Tentang Penerimaan Peserta Didik Baru Pada Tamatan Kanak-kanak, Sekolah Dasar,Sekolah Menengah Pertama, Sekolah Menengah Atas dan Sekolah Menengah Kejuruan. Jakarta: Kementerian Pendidikan Nasional dan Kebudayaan Republik Indonesia.

Kholiq, Abdul. 2016. "Hubungan Antara Kemampuan Membaca Al-Qur'an Dengan Kemampuan Menulis Ayat Al-Qur'an Siswa MTs NU Darussalam Kecamatan Mijen Kota Semarang 2015/2016”. Fakultas Ilmu Tarbiyah dan Keguruan. Skripsi. Semarang: Universitas Islam Negeri Walisongo.

Margono, S. 2010. Metodologi Penelitian Pendidikan. Jakarta: Rineka Cipta.

Penulis, Tim. 2010. Pendidikan Agama Islam. Solo: PT Tiga Serangkai Pustaka Mandiri.

Rahmi, Alfi. 2015. Diagnosis Kesulitan Belajar. Batam: P3SDM Melati.

Ritonga, A Rahman. 2016. Paradigma Pendidikan dalam Perspektif Hadis; Memahami Hadishadis Pendidikan Secara Integratif. Padang: Hayfa Press.

Rizally, Mar'atun Aslamiyah. 2011. "Korelasi Antara Usia Kronologis Awal Masuk Sekolah Terhadap Prestasi Belajar" dalam Jurnal Pendidikan Khusus Volume 3 Nomor 3. Padang: Jurusan Pendidikan Luar Biasa Fakultas Ilmu Pendidikan Universitas Negeri Padang.

Sugiyono. 2010. Metode Penelitian Pendidikan. Bandung: Alfabeta.

Syah, Muhibbin. 2010. Psikologi Belajar. Jakarta: Rajawali Pers. 